\title{
Multiple-Organ Extracorporeal Support Therapies in Critically Ill Patients
}

\author{
José Lucas Daza', María C. Correcha Ferro², Andrés David Cardenas 3 , Luis Daza4, Emilio Rey5, \\ Jonathan de Jong², John Galindo5 , Gerardo Gutiérrez¹, Luis Puello ${ }^{1}$, Yaroslad de la Cruz ${ }^{1}$
}

\author{
${ }^{1}$ Nephrology Unit, Hospital De Clinicas, Buenos Aires, Argentina \\ ${ }^{2}$ Department of Medicine, Manizales University, Manizales, Colombia \\ ${ }^{3}$ Department of Medicine, Cooperativa University, Ibague, Colombia \\ ${ }^{4}$ Hematolology Unit, Fluminense University, Rio de Janeiro, Brasil \\ ${ }^{5}$ Nephrology Unit, Fresenius Medical Care, Ibague, Colombia \\ Email: montelucaz@gmail.com
}

How to cite this paper: Daza, J.L., Ferro, M.C.C., Cardenas, A.D., Daza, L., Rey, E., de Jong, J., Galindo, J., Gutiérrez, G., Puello, L. and de la Cruz, Y. (2021) Multiple-Organ Extracorporeal Support Therapies in Critically Ill Patients. Open Journal of Nephrology, 11, 281-293.

https://doi.org/10.4236/ojneph.2021.112023

Received: May 14, 2021

Accepted: June 21, 2021

Published: June 24, 2021

Copyright $\odot 2021$ by author(s) and Scientific Research Publishing Inc. This work is licensed under the Creative Commons Attribution International License (CC BY 4.0).

http://creativecommons.org/licenses/by/4.0/

\begin{abstract}
The critically ill patient is capable of presenting a multiple organ dysfunction syndrome (MODS) caused by different diseases, which can be infectious (sepsis, septic shock) as well as non-infectious (pancreatitis, large surgeries, traumatic injuries, burn patients and brain injuries), this syndrome is characterized by global hemodynamic and organ perfusion alterations accompanied by an uncontrolled and marked inflammatory response unresponsive to pharmacological treatment due to which extracorporeal organ support can be a viable option. Acute renal lesion can occur in up to $60 \%$ of patients receiving intensive care, and close to $10 \%-20 \%$ require renal replacement therapy (RRT) globally this can be provided as peritoneal dialysis (PD) or intermittent hemodialysis (IHD), continuous renal replacement therapy (CRRT), hybrid therapies known as sustained slow efficiency dialysis (SLED), which combines the benefits IHD and CRRT, slow continuous ultrafiltration (SCUF). Extracorporeal membrane oxygenation (ECMO) and extracorporeal elimination of $\mathrm{CO}_{2}$, have been used more frequently lately, these are temporal artificial support used for respiratory and/or cardiac insufficiency that is refractory to conventional treatment. Acute liver failure in adults has a mortality rate close to $50 \%$ furthermore one-third of patients hospitalized for cirrhosis are likely to progress to acute liver failure which will drastically increase its mortality. Based on concepts of albumin dialysis, one of its most known is the following: Molecular Adsorbent Recirculating System (MARS), Fractionated Plasma Separation and Absorption-FPSA (Prometheus ${ }^{\circledR}$ ) and also, hemoperfusion with different cartridges used in different extracorporeal therapies, used in liver failure, rhabdomyolysis, cytokine release syndrome and more in the context of the pandemic covid19. The objective of this review is to know the different extracorporeal therapies and the therapeutic utility in critical patients.
\end{abstract}




\section{Keywords}

MODS (Multiple Organ Dysfunction Syndrome), RRT (Renal Replacement Therapy, CRRT (Continuous Renal Replacement Therapy), SLED (Slow Efficiency Dialysis ECMO (Extracorporeal Membrane Oxygenation), ECCO2 (Extracorporeal Elimination of Carbon Dioxide), ARDS (Acute Respiratory Distress Syndrome), AKI (Acute Kidney Injury)

\section{Introduction}

Critically ill patients are known to be at risk of developing organ dysfunction during their stay within the intensive care unit, when this dysfunction compromises three or more organs this mortality can reach up to $90 \%$ [1]. Multiple organ dysfunction syndrome (MODS) can be classified as primary or secondary.

Primary MODS: the result of well-defined aggression wherein the organ dysfunction presents in an early stage and can be attributed directly to the aggression itself (e.g. kidney injury due to rhabdomyolysis).

Secondary MODS: organ dysfunction that is not a direct response to aggression itself, but a consequence of a host-regulated response (e.g. acute respiratory distress syndrome presenting in a patient with pancreatitis) [2].

Early deterioration of an organ's function is often followed by dysfunction or damage to other organs resulting in negative interactions with different systems [3] an example of this is the cardiorenal syndrome, hepatorenal syndrome, alterations within the cardiopulmonary circulation, which become a vicious cycle with deleterious consequences.

The different therapies available for multiple organ dysfunction syndrome include oxygenation and ventilatory support (invasive mechanical ventilation and non-invasive $[\mathrm{MV}]$, veno-venous (VV) extracorporeal membrane oxygenation [ECMO].

And extracorporeal carbon dioxide elimination [ECCO2], mechanical circulatory support (intra-aortic balloon pump, veno-arterial (VA) ECMO, percutaneous and surgical ventricular assist devices (PVAD) and total artificial heart), renal replacement therapy (RRT) and extracorporeal liver support (molecular adsorbent recirculating system, plasmapheresis and hemoperfusion [4].

MODS: defined as the acute and potentially reversible dysfunction of two or more organ systems that are triggered by multiple clinically diverse factors [5].

Presenting as a hypo-metabolic and immunosuppressed state with clinical and biochemical evidence of a reduced function of various organ systems of the body which develops after an injury or acute illness [6].

The mechanism of injury or infection implies a complex interaction of different interdependent factors, such as genetic factors and this generates differences of the gene expression and its proteome this could explain the individual differences seen in the likelihood of presenting MODS and its severity, also the im- 
portance of patients' comorbidities making them more susceptible to organ deterioration [7].

Macrocirculatory changes resulting in systemic vasoplegia due to nitric oxide synthase induction secondary to inflammation and reduced delivery of oxygen (DO2) to different tissues, microcirculatory changes producing microvascular thrombi, reduced red blood cell deformity, an increase in blood viscosity, endothelial and glycocalyx dysfunction [8].

The dysregulation of pro-inflammatory factors triggers a systemic inflammatory response mediated by multiple cytokines (for example, IL6, TNF alpha, IFN gamma), the coagulation cascade is activated by the tissue factor, endotoxins, cytokines and bacterial antigens, neuroendocrine factors which produce immunosuppression mediates the response to stress through the involvement of suprarenal hormones, a hypothyroid state due to the production of inverse T3 which is inert [9], mitochondrial dysfunction which could be mediated by humoral factors that contribute to cellular dysoxia and organ dysfunction, this organ dysfunctions plays a fundamental role in the underlying process of MODS [10].

Due to the complex and diverse nature of the physiopathology of this syndrome it is common for patients to develop negative interactions between the different organs the combined dysfunction of the kidney and liver is common and is described within the different types of hepatorenal syndromes [11].

Cardiac dysfunction resulting in cardiorenal syndrome, alterations of the cardiopulmonary circulation, acute respiratory distress syndrome, the intestine and kidney can also present reciprocal negative interactions and due to primary alterations within the host's intestinal microbiota and a disturbance of the intestinal barrier's function which leads to systemic inflammation [12].

\section{Extracorporeal Therapies}

The most frequent cause of severe acute kidney injury in the ICU is sepsis which oftentimes requires RRT in the form of intermittent hemodialysis (IHD), peritoneal dialysis (PD) and extended hemodialysis (sustained low efficiency dialysis: SLED) or CRRT (continuous renal replacement therapy) [13]. The objectives of renal substitution therapy (RST) are the elimination of solutes and water, and the correction of electrolyte abnormalities and the normalization of acid-base alterations in some observational studies involving septic patients being treated with RST can present a rapid and significant improvement of their hemodynamic state, with a reduced need for vasopressor support few hours after the implementation of an extracorporeal circulation [14].

Regarding the continuous modalities of renal replacement therapy (CRRT), these include continuous veno-venous hemofiltration (CVVH), continuous veno-venous hemodiafiltration (CVVHDF), hybrid therapy (HT) which a recently discovered modality of acute renal replacement therapy SLED (daily sustained low efficiency dialysis), prolonged intermittent hemodialysis [15] which combines the benefits of intermittent hemodialysis pertaining to solute removal and the hemodynamic stability related to CRRT (Figure 1). 


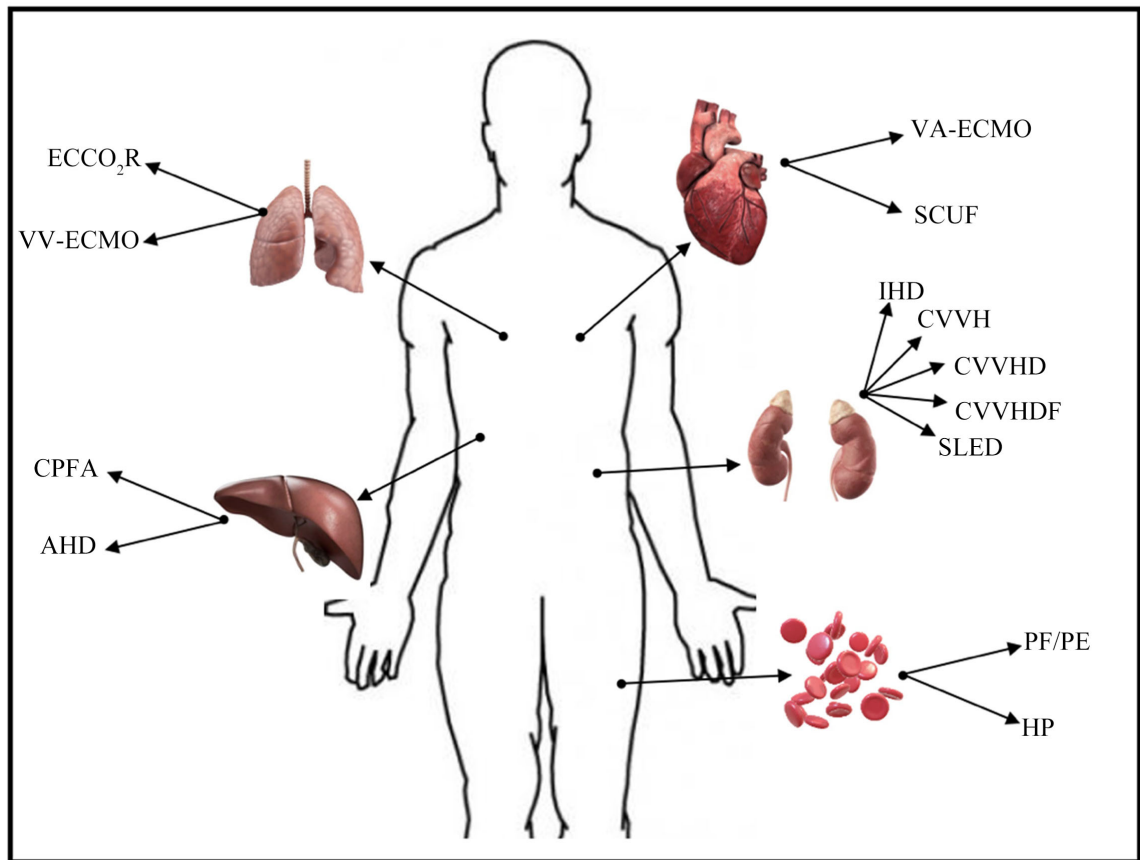

Figure 1. Schematic representation of extracorporeal therapy methods. ECCO2R, extracorporeal extraction of $\mathrm{CO}_{2}$; VA-ECMO, veno-arterial extracorporeal membrane oxygenation; SCUF, slow continuous ultra-filtration; CVVH, continuous veno-venous hemofiltration; CVVHD, continuous veno-venous hemodialysis; CVVHDF, continuous veno-venous hemodiafiltration; SLED, sustained low efficiency dialysis; IHD, intermittent hemodialysis; PF, plasmapheresis; PE, plasma exchange; HP, hemoperfusion; AHD, albumin hemodialysis; CPFA, coupled plasma filtration adsorption; VVECMO, veno-venous extracorporeal membrane oxygenation.

The KDIGO (Kidney Disease Improving Global Outcomes) guidelines for acute kidney injury (AKI) recommend the use of CRRT for patients presenting with hemodynamic instability or intracranial hypertension this is based on clinical factors specific to the patient [16] these advantages from the CRRT have not been demonstrated in randomized clinical trials.

A recent meta-analysis did not encounter any significant difference in the renal recovery and in-hospital mortality during ICU admission between patients presenting with AKI receiving CRRT and those receiving SLED, furthermore those patients with AKI receiving CRRT had a higher mortality rate during ICU admission, compared to those who received IHD. All three modalities have their own advantages and disadvantages. This highlights the need for a well-designed more rigorous clinical trial with large cohorts to explore the differences related to renal recovery, in-hospital mortality and ICU mortality rate comparing the different types of RST [17].

\section{Hemoperfusion}

Sepsis is one of the main causes of morbidity and mortality within the intensive care units worldwide, this is due to organ dysfunction [18]. This implies an early activation of pro- and anti-inflammatory pathways, through a dual mechanism 
which induces cytokine-mediated cellular damage and a state of gravely deteriorated immunity (immuno-paralysis) [19]. Mediators of pro-inflammatory actions, such as tumoral necrosis factor alpha (TNF- $\alpha$ ) interleukin-1, interleukin-6 and anti-inflammatory cytokines such as interleukin-10, interleukin-4. Both responses can take place at the same time and not in a sequential manner as was previously thought [20].

These pro-inflammatory cytokines are the main factors responsible of the activation of leucocytes, oxidative stress, glycocalyx and endothelial dysfunction as well as alteration of the activation pathway of nitric oxide, which results in a reduced deformability of the red blood cell and an alteration of the hemorrheology, loss of microvascular tone, microcirculatory shunting, tissue edema and a shortage of oxygen extraction [21] [22].

Due to the presence of these different sepsis phenotypes and the massive release of cytokines. Various extracorporeal blood purification therapies have been proposed as a strategy to improve the results of septic patients, weakening the systemic expression of pro-inflammatory factors and anti-inflammatory mediators and restoring the homeostasis of the immune system [23] hemoadsorption places sorbents in direct contact with the blood and the extracorporeal circuit, the solutes are attracted by the sorbents through a series of hydrophobic interactions and ionic attractions, it is important that this elimination is non-specific for a wide spectrum of inflammatory mediators [24], there are different cartridges available on the market currently, the technology (CytoSorbents Corporation Monmouth Junction, NJ, USA) is based on cartridges containing copolymer pearls of biocompatible polystyrene-divinylbenzene capable of eliminating various cytokines in vitro as well as in vivo [25]. This preclinical data in a sepsis mouse model is encouraging, as it shows a reduction in circulating cytokines, an increase in arterial pressure and improved short-term survivability rates with hemadsorption Cytosorb [26] however these studies are observational, with limitations, this preliminary data justifies more investigation to clarify the mechanisms of this effect in a larger environment [27].

\section{Plasmapheresis}

Plasmapheresis is an extracorporeal filtration technique in which the plasma is separated from its remaining blood components and is exchanged for a replacement liquid, generally fresh frozen plasma (FFP) or albumin, according to the disease, the general of state of coagulation and the immune system [28] [29] the basic premise of therapeutic apheresis is centered around eliminating or reducing the levels of certain pathological substances within the plasma, which could be auto-antibodies, immune complexes, cryoglobulins, light myeloma chains, endotoxins, lipoproteins containing cholesterol or other substances [30].

The diseases known to cause MODS, in which an overwhelming systemic immune response is triggered by the release of pro-inflammatory cytokines and damage associated molecular patterns (DAMP) as can be seen in the case of 
acute liver failure, where acute necrosis and at times a massive release of the hepatocytes [31] [32] the extracorporeal elimination of circulating excess pro-inflammatory molecules could be a therapeutic option.

It has been used with success in patients with severe sepsis, MODS and fulminant SARS-CoV infection, however its benefits in severe ARDS are not clear [33].

The use of plasmapheresis with a variety of adsorption cartridges has been a subject of various cohort studies and clinical trials, it is supposed that its benefit comes from its reduction of inflammatory cytokines, and the cytokine release syndrome (CRS) [34] [35] [36] (See Table 1).

Small observational studies have shown that plasmapheresis when used with adsorption cartridges is associated with a discrete improvement in the biomarkers related to cytokine release syndrome (CRS), ARDS, septic shock and MODS related to fulminant COVID-19, it also appears to be of low risk despite the severity of these patients. More randomized clinical trials of larger scale are required to confirm the findings of these observational studies [37] [38].

\section{Liver Dialysis with Albumin/Continuous Adsorptive Plasmafiltration}

The estimated frequency of liver failure, either as an isolated case of acute liver failure or as an acute worsening of a chronic form of liver failure across all age groups in the United States is approximately of 17 cases per 100.000 inhabitants annually, with a mortality of $50 \%$ [39].

Within this context and due to the shortage of organs available for transplant, different efforts have been made to find therapeutic alternatives for these patients awaiting a new organ (bridge to transplant therapy) or for patients not in need of a transplant but with a possibility of recovery.

Two systems are used, the Molecular Adsorbent Recirculating System (MARS), the single pass albumin dialysis system (SPAD) and a fractionated plasma separation and adsorption system-FPSA (Prometheus). These systems are based on the concept of albumin dialysis and, therefore, are capable of eliminating albumin-linked toxins which accumulate in the context of liver failure.

Table 1. Cytokine release syndrome criteria (one or more of the following criteria).

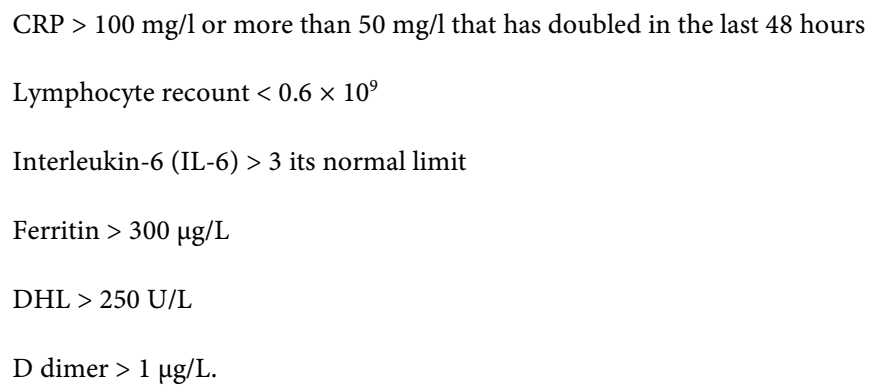

CRP: C-reactive Protein; DHL: deshydrogenasa lactic. 
The difference between these two systems (MARS) and the fractionated plasma separation and adsorption system: FPSA (Prometheus) is that MARS utilizes a solution of exogenous albumin and the available Prometheus system allows for the patient's own albumin to enter the first circuit using the AlbuFlow ${ }^{\circledR}$ (Molecular cut-off of $250 \mathrm{kDa}$ ), this albumin is reactivated and returns to the circulation using a neutral resin adsorbent (Prometh $\left.{ }^{\circledR} 01\right)$ and an anion exchange column (Prometh ${ }^{\circledR}$ 02), afterwards, the blood enters a second circuit where its treated through conventional high-flow hemodialysis prior to returning to the patient [40].

There are no precise recommendations on the most effective moment to start these systems of artificial liver support, meanwhile and in absence of alternative options to support this vital organ, it is difficult to criticize the cautionary use of these safe artificial liver devices, as a "rescue" therapy for patient suffering from acute liver failure [41].

\section{Veno-Venous Ecmo (VV) - Veno-Arterial (VA)}

Extracorporeal membrane oxygenation is designed to provide a temporal extracorporeal respiratory support through the use of artificial oxygenation membranes in the case of pulmonary failure not responsive to conventional treatment, with clear indications according to current guidelines (ELSO) [42].

In patients with respiratory insufficiency, the common approach is through a VVECMO bypass, in contrast to VA-ECMO it is a temporal mechanical circulatory support it is most frequently used in patients with refractory cardiogenic shock and cardiac arrest [43].

Although septic shock in adults has generally been described as a vasoplegic shock or distributive with high cardiac output [44], a possible complication of septic shock is sepsis-induced cardiomyopathy, this condition is often characterized by a reversible left ventricular dilation accompanied by a reduced left ventricular function [45] which results in a sepsis-induced cardiogenic shock, theoretically the use of VA-ECMO could be considered, however it is a controversial treatment strategy for septic shock. In-hospital mortality rates reported for patients with sepsis-induced cardiogenic shock receiving VA-ECMO were quite inconsistent making it difficult to conclude its safety and benefits [46].

Myocardial infarction is the most common cause of cardiogenic shock, accounting for $80 \%$ of total cases [47]. The most severe cases can be treated with mechanical circulatory support as a bridge to recovery of cardiac function or bridge to cardiac transplant, among these is VA-ECMO [48].

Although non-randomized clinical trials suggest advantages in the survival rates of patients with cardiogenic shock receiving early VA-ECMO. Nevertheless $39 \%$ of the cases developed complications due to an increased left ventricular afterload which could affect the recovery rate of the myocardium, severe pulmonary edema [49].

A recent meta-analysis included 3997 patients, among them 1696 (42\%) received VA-ECMA combined with a concomitant strategy for left ventricular un- 
loading, such as intra-aortic balloon pump or other ventricular devices and found and a reduction in mortality [50]. Reperfusion and early implantation of circulatory support strategies are essential in improving the overall results in cardiogenic shock.

\section{Extracorporeal Carbon Dioxide Removal (ECCO2)}

These devices remove $\mathrm{CO}_{2}$ from the venous blood, through a membrane which is similar to those of ECMO devices, its fundamental difference is based on the usage of much lower blood flows and therefore arterial or venous cannulas of smaller sizes [51] its main utility is for patients with severe ARDS that develop important hypercapnia from a protective ventilation strategy [52].

Hypercapnia generates pulmonary vasoconstriction which in turn will develop into pulmonary hypertension that contributes to the appearance of cor pulmonale in patients with ARDS and increase its mortality [53].

In comparison with VV-ECMO, where a lower number of complications has been associated with the newer systems due to a lower degree of invasiveness and due to technological advances. also the need for lower blood flow rates of 0.4 to $0.1 \mathrm{~L} / \mathrm{min}$ required for the elimination of $\mathrm{CO}_{2}$ which can be achieved with cannulas of sizes between 14 and $18 \mathrm{Fr}$ [54].

Table 2. Available extracorporeal support devices and strategies.

\begin{tabular}{ll}
\hline TYPE OF THERAPY & MECHANISM \\
\hline HEMOPERFUSION & $\begin{array}{l}\text { The passage of the blood through a column } \\
\text { containing adsorbent particles (actived charcoal or } \\
\text { resin). }\end{array}$
\end{tabular}

Separation of the blood components and exchanged for a replacement fluid, usually fresh frozen plasma (PFC) or albumin, depending on the disease, the general state of coagulation and the immune system.

LIVER DIALYSIS WITH

ALBUMIN

/CONTINUOUS

ADSORPTIVE

PLASMAFILTRATION

Eliminate albumin-bound toxins that accumulate in the context of liver failure.

Actually exist the molecular recirculation adsorbent system (MARS), the one-step albumin dialysis system (SPAD) and a fractionated plasma separation and adsorption system - FPSA (Prometheus).

Extracorporeal membrane oxygenation provide

VENO-VENOUS ECMO

$\begin{array}{ll}\text { (VV) - } & \text { through the use of artificial oxygenation membrane } \\ \text { VENO-ARTERIAL (VA) in the case of pulmonary insufficiency that does not }\end{array}$ temporary extracorporeal respiratory support respond to treatment.

Extract $\mathrm{CO}_{2}$ from venous blood, through a membrane similar to those of ECMO devices, its difference is based on the use of much lower blood flows and therefore smaller arterial or venous

cannulas.
CARBON DIOXIDE REMOVAL (ECCO2)

\section{OBJECTIVE}

Strategy to improve the evolution of septic patients, reducing the systemic expression of pro-inflammatory factors and anti-inflammatory mediators and restoring the balance of the immune system.

The basic premise of therapeutic apheresis focuses on eliminating or reducing the levels of certain pathological substances in the plasma, which can be autoantibodies, immune complexes, cryoglobulins, light myeloma chains, endotoxins, cholesterol-containing lipoproteins or other substances.

There are no precise indications on the opportune use. In the absence of alternative options to support this vital organ, it is difficult to restrict the cautious use of these safe artificial liver devices, as "salvage therapy" for patients suffering from acute liver failure. There are no precise indications on the opportune use.

Improve cardiovascular and respiratory function with the extracorporeal oxygenation.

In patients with respiratory insufficiency the VV-ECMO bypass is the most used. The use of VA-ECMO is frequently used in patients with refractory cardiogenic shock and cardiac arrest.

The utility is for patients with severe ARDS who had an important hypercapnia from a protective ventilation strategy.

ECMO: extracorporeal membrane oxygenation; ARDS: acute respiratory distress syndrome. 
It has become a therapeutic option that's situated between conventional ventilatory support and total respiratory support (ECMO), it's a therapeutic option that must be considered in patients with severe ARDS, however more future clinical trials are needed to prove its effectiveness and safety.

\section{Conclusions}

Multiple organ dysfunction syndrome is very common among critically ill patients with an elevated mortality rate and its annual incidence is close to $51 \%$, this incidence has been rising during the last ten years, no specific treatment exists [5].

Advances within the area of multiple-organ extracorporeal therapy have not been able to change the mortality rate in a significant way [55] new machines with improved technologies are needed to avoid negative interactions between the different organs, as well as more studies looking to establish an ideal moment for these interventions, to find out if early implementation has an impact in the recovery of organs and to optimize the use of resources and improving results.

The Prevention It is the best treatment for multiple organ dysfunction syndrome. Fast and optimal volume at resuscitation, adequate protection myocardial in cardiac operations, proper nutrition detection and adequate treatment of low spending cardiac arrest, appropriate use of antibiotics (Table 2).

\section{Conflicts of Interest}

The authors declare no conflicts of interest regarding the publication of this paper.

\section{References}

[1] Knaus, W.A., Draper, E.A., Wagner, D.P., et al. (1985) APACHE II: A Severity of Disease Classification System. Critical Care Medicine, 13, 818-829. https://doi.org/10.1097/00003246-198510000-00009

[2] Seymour, C.W., Liu, V.X., Iwashyna, T.J., et al. (2016) Evaluación de los criterios clínicos para la sepsis: Para las definiciones del tercer consenso internacional para la sepsis y el shock séptico (Sepsis-3). JAMA, 315, 762. https://doi.org/10.1001/jama.2016.0288

[3] Ziesmann, M.T. and Marshall, J.C. (2018) Multiple Organ Dysfunction: The Defining Syndrome of Sepsis. Surgical Infections, 19, 184-190. https://doi.org/10.1089/sur.2017.298

[4] Ronco, C. (2006) Recent Evolution of Renal Replacement Therapy in the Critically Ill Patient. Critical Care, 10, 123. https://doi.org/10.1186/cc4843

[5] Barie, P.S. and Hydo, L.J. (2000) Epidemiology of Multiple Organ Dysfunction Syndrome in Critical Surgical Illness. Surgical Infections, 1, 173-185. https://doi.org/10.1089/109629600750018105

[6] Boomer, J.S., To, K., Chang, K.C., et al. (2011) Immunosuppression in Patients Who Die of Sepsis and Multiple Organ Failure. JAMA, 306, 2594-2605. https://doi.org/10.1001/jama.2011.1829 
[7] De Backer, D., Orbegozo Cortes, D., Donadello, K. and Vincent, J.L. (2014) Pathophysiology of Microcirculatory Dysfunction and the Pathogenesis of Septic Shock. Virulence, 5, 73-79. https://doi.org/10.4161/viru.26482

[8] Mongardon, N., Dyson, A. and Singer, M. (2009) Is MOF an Outcome Parameter or a Transient, Adaptive State in Critical Illness? Current Opinion in Critical Care, 15, 431-436. https://doi.org/10.1097/MCC.0b013e3283307a3b

[9] Sakr, Y., Dubois, M.J., De Backer, D., Creteur, J. and Vincent, J.L. (2004) Persistent Microcirculatory Alterations Are Associated with Organ Failure and Death in Patients with Septic Shock. Critical Care Medicine, 32, 1825-1831. https://doi.org/10.1097/01.CCM.0000138558.16257.3F

[10] De Backer, D., Ospina-Tascon, G., Salgado, D., Favory, R., Creteur, J. and Vincent, J.L. (2010) Monitoring the Microcirculation in the Critically Ill Patient: Current Methods and Future Approaches. Intensive Care Medicine, 36, 1813-1825.

https://doi.org/10.1007/s00134-010-2005-3

[11] Ospina-Tascon, G., Neves, A.P., Occhipinti, G., Donadello, K., Buchele, G., Simion, D., Chierego, M., Oliveira Silva, T., Fonseca, A., Vincent, J.L., et al. (2010) Effects of Fluids on Microvascular Perfusion in Patients with Severe Sepsis. Intensive Care Medicine, 36, 949-955. https://doi.org/10.1007/s00134-010-1843-3

[12] Jacobs, M.C., Haak, B.W., Hugenholtz, F. and Wiers-inga, W.J. (2017) Gut Microbiota and Host Defense in Critical Illness. Current Opinion in Critical Care, 23, 257-263. https://doi.org/10.1097/MCC.0000000000000424

[13] Uchino, S., Kellum, J.A., Bellomo, R., Doig, G.S., Morimatsu, H., Morgera, S., Schetz, M., Tan, I., Bouman, C., Macedo, E., Gibney, N., Tolwani, A. and Ronco, C. (2005) Beginning and Ending Supportive Therapy for the Kidney (BEST Kidney) Investigators. Acute Renal Failure in Critically Ill Patients: A Multinational, Multicenter Study. JAMA, 294, 813-818. https://doi.org/10.1001/jama.294.7.813

[14] Tetta, C., Cavaillon, J.M., Schulze, M., Ronco, C., Ghezzi, P.M., Camussi, G., Serra, A.M., Curti, F. and Lonnemann, G. (1998) Removal of Cytokines and Activated Complement Components in an Experimental Model of Continuous Plasma Filtration Coupled with Sorbent Adsorption. Nephrology Dialysis Transplantation, 13, 1458-1464. https://doi.org/10.1093/ndt/13.6.1458

[15] Gatward, J.J., Gibbon, G.J., Wrathall, G. and Padkin, A. (2008) Renal Replacement Therapy for Acute Renal Failure: A Survey of Practice in Adult Intensive Care Units in the United Kingdom. Anaesthesia, 63, 959-966. https://doi.org/10.1111/j.1365-2044.2008.05514.x

[16] Kidney Disease: Improving Global Outcomes (KDIGO) Acute Kidney Injury Work Group (2012) KDIGO Clinical Practice Guideline for Acute Kidney Injury. Kidney International, 2, 1-138.

[17] Zhao, Y.Y. and Chen, Y.F. (2020) Effect of Renal Replacement Therapy Modalities on Renal Recovery and Mortality for Acute Kidney Injury: A PRISMA-Compliant Systematic Review and Meta-Analysis. Seminars in Dialysis, 33, 127-132.

[18] Martin, G.S., Mannino, D.M., Eaton, S., et al. (2003) The Epidemiology of Sepsis in the United States from 1979 through 2000. The New England Journal of Medicine, 348, 1546-1554. https://doi.org/10.1056/NEJMoa022139

[19] Kellum, J.A., Kong, L., Fink, M.P., Weissfeld, L.A., Yealy, D.M., Pinsky, M.R., et al. (2007) Understanding the Inflammatory Cytokine Response in Pneumonia and Sepsis: Results of the Genetic and Inflammatory Markers of Sepsis (Genims) Study. Archives of Internal Medicine, 167, 1655-1663. https://doi.org/10.1001/archinte.167.15.1655 
[20] Weighardt, H., Heidecke, C.D., Emmanuilidis, K., et al. (2000) Sepsis after Major Visceral Surgery Is Associated with Sustained and Interferon-Gamma-Resistant Defects of Monocyte Cytokine Production. Surgery, 127, 309-315. https://doi.org/10.1067/msy.2000.104118

[21] Donati, A., Domizi, R., Damiani, E., Adrario, E., Pelaia, P. and Ince, C. (2013) From Macrohemodynamic to the Microcirculation. Critical Care Research and Practice, 2013, Article ID: 892710. https://doi.org/10.1155/2013/892710

[22] Marechal, X., Favory, R., Joulin, O., Montaigne, D., Hassoun, S., Decoster, B., Zerimech, F. and Neviere, R. (2008) Endothelial Glycocalyx Damage during Endotoxemia Coincides with Microcirculatory Dysfunction and Vascular Oxidative Stress. Shock, 29, 572-576. https://doi.org/10.1097/SHK.0b013e318157e926

[23] Neri, M., Villa, G., Garzotto, F., et al. (2016) Nomenclature for Renal Replacement Therapy in Acute Kidney Injury: Basic Principles. Critical Care, 20, Article No. 318.

[24] Cruz, D.N., Antonelli, M., Fumagalli, R., Foltran, F., Brienza, N., Donati, A., et al. (2009) Early Use of Polymyxin B Hemoperfusion in Abdominal Septic Shock: The EUPHAS Randomized Controlled Trial. JAMA, 301, 2445-2452. https://doi.org/10.1001/jama.2009.856

[25] Kellum, J.A., Song, M. and Venkataraman, R. (2004) Hemoadsorption Removes Tumor Necrosis Factor, Interleukin-6, and Interleukin-10, Reduces Nuclear Factor-Kappab DNA Binding, and Improves Short-Term Survival in Lethal Endotoxemia. Critical Care Medicine, 32, 801-805. https://doi.org/10.1097/01.CCM.0000114997.39857.69

[26] Peng, Z.Y., Carter, M.J. and Kellum, J.A. (2008) Effects of Hemoadsorption on Cytokine Removal and Short-Term Survival in Septic Rats. Critical Care Medicine, 36, 1573-1577. https://doi.org/10.1097/CCM.0b013e318170b9a7

[27] Zuccari, S., et al. (2020) Changes in Cytokines, Haemodynamics and Microcirculation in Patients with Sepsis/Septic Shock Undergoing Continuous Renal Replacement Therapy and Blood Purification with CytoSorb. Blood Purification, 49, 107-113. https://doi.org/10.1159/000502540

[28] Ruiz, D.D., Miguel, F.S.F., de Molina, G.F.J., Ubeda-Iglesias, A., Pérez, N.A. and Forés, R.J. (2017) Plasmapheresis and Other Extracorporeal Filtration Techniques in Critical Patients. Medicina Intensiva, 41, 174-187. https://doi.org/10.1016/j.medin.2016.10.005

[29] Nakanishi, T., Suzuki, N., Kuragano, T., Nagasawa, Y. and Hasuike, Y. (2014) Current topics in Therapeutic Plasmapheresis. Clinical and Experimental Nephrology, 18, 41-49. https://doi.org/10.1007/s10157-013-0838-0

[30] Williams, M.E. and Balogun, R.A. (2014) Principles of Separation: Indications and Therapeutic Targets for Plasma Exchange. Clinical Journal of the American Society of Nephrology, 9, 181-190. https://doi.org/10.2215/CJN.04680513

[31] Bernal, W. and Wendon, J. (2013) Acute Liver Failure. The New England Journal of Medicine, 369, 2525-2534. https://doi.org/10.1056/NEJMra1208937

[32] Stravitz, R.T., Bowling, R., Bradford, R.L., et al. (2013) Role of Procoagulant Microparticles in Mediating Complications and Outcome of Acuteliver Injury/Acute Liver Failure. Hepatology, 58, 304-313. https://doi.org/10.1002/hep.26307

[33] Patel, P., et al. (2011) Use of Therapeutic Plasma Exchange as a Rescue Therapy in 2009 pH1N1 Influenza A-An Associated Respiratory Failure and Hemodynamic Shock. Pediatric Critical Care Medicine, 12, e87-e89.

[34] Dellinger, R.P., Bagshaw, S.M., Antonelli, M., et al. (2018) Effect of Targeted Polymyxin B Hemoperfusion on 28-Day Mortality in Patients with Septic Shock and 
Elevated Endotoxin Level: The EUPHRATES Randomized Clinical Trial. JAMA, 320, 1455-1463. https://doi.org/10.1001/jama.2018.14618

[35] Sloan, S.R., Andrzejewski Jr., C., Aqui, N.A., Kiss, J.E., Krause, P.J. and Park, Y.A. (2015) Role of the Rapeuticapheresis in Infectious and Inflammatory Diseases: Current Knowledge and Unanswered Questions. Journal of Clinical Apheresis, 30, 259-264. https://doi.org/10.1002/jca.21370

[36] Faqihi, F., et al. (2020) Therapeutic Plasma Exchange in Adult Critically Ill Patients with Life-Threatening SARS-CoV-2 Disease: A Pilot Study. Journal of Critical Care, 60, 328-333. https://doi.org/10.1016/j.jcrc.2020.07.001

[37] Knaup, H., Stahl, K., Schmidt, B.M.W., et al. (2018) Early Therapeutic Plasma Exchange in Septic Shock: A Prospective Open-Label Nonrandomized Pilot Study Focusing on Safety, Hemodynamics, Vascular Barrier Function, and Biologic Markers. Critical Care, 22, 285. https://doi.org/10.1186/s13054-018-2220-9

[38] Naghavi, M., Abajobir, A.A., Abbafati, C., Abbas, K.M., Abd-Allah, F., Abera, S.F., et al. (2017) Global, Regional, and National Age-Sex Specific Mortality for 264 Causes of Death, 1980-2016: A Systematic Analysis for the Global Burden of Disease Study 2016. The Lancet, 390, 1151-1210.

https://doi.org/10.1016/S0140-6736(17)32152-9

[39] Moreau, R. and Arroyo, V. (2015) Acute-on-Chronic Liver Failure: A New Clinical Entity. Clinical Gastroenterology and Hepatology, 13, 836-841. https://doi.org/10.1016/j.cgh.2014.02.027

[40] Grodzicki, M., Kotulski, M., Leonowicz, D., Zieniewicz, K. and Krawczyk, M. (2009) Results of Treatment of Acute Liver Failure Patients with Use of the Prometheus FPSA System. Transplantation Proceedings, 41, 3079-3081. https://doi.org/10.1016/j.transproceed.2009.08.024

[41] Nakae, H., Eguchi, Y., Saotome, T., Yoshioka, T., Yoshimura, N., Kishi, Y., et al. (2010) Multicenter Study of Plasma Diafiltration in Patients with Acute Liver Failure. Therapeutic Apheresis and Dialysis, 14, 444-450. https://doi.org/10.1111/j.1744-9987.2010.00864.x

[42] ELSO (2017) Guidelines for Cardiopulmonary Extracorporeal Life Support Extracorporeal Life Support Organization, Version 1.4.

[43] Keebler, M.E., Haddad, E.V., Choi, C.W., et al. (2018) Venoarterial Extracorporeal Membrane Oxygenation in Cardiogenic Shock. JACC Heart Fail, 6, 503-516.

https://doi.org/10.1016/j.jchf.2017.11.017

[44] Angus, D.C. and van der Poll, T. (2013) Severe Sepsis and Septic Shock. The New England Journal of Medicine, 369, 840-851. https://doi.org/10.1056/NEJMra1208623

[45] Sato, R. and Nasu, M. (2015) A Review of Sepsis-Induced Cardiomyopathy. Journal of Intensive Care, 3, 48. https://doi.org/10.1186/s40560-015-0112-5

[46] Barbaro, R.P., Odetola, F.O., Kidwell, K.M., et al. (2015) Association of Hospital-Level Volume of Extracorporeal Membrane Oxygenation Cases and Mortality. Analysis of the Extracorporeal Life Support Organization Registry. American Journal of Respiratory and Critical Care Medicine, 191, 894-901. https://doi.org/10.1164/rccm.201409-1634OC

[47] Mebazaa, A., Combes, A., van Diepen, S., et al. (2018) Management of Cardiogenic Shock Complicating Myocardial Infarction. Intensive Care Medicine, 44, 760-773. https://doi.org/10.1007/s00134-018-5214-9

[48] Guglin, A., Zucker, M.J., Bazan, V.M., et al. (2019) Venoarterial ECMO for Adults JACC Scientific Expert Panel. JACC, 73, 698-716. 
[49] Muller, G., Flecher, E., Lebreton, G., et al. (2016) The ENCOURAGE Mortality Risk Score and Analysis of Long-Term Outcomes after VA-ECMO for Acute Myocardial Infarction with Cardiogenic Shock. Intensive Care Medicine, 42, 370-378. https://doi.org/10.1007/s00134-016-4223-9

[50] Russo, J.J., Aleksova, N., Pitcher, I., et al. (2019) Left Ventricular Unloading during Extracorporeal Membrane Oxygenation in Patients with Cardiogenic Shock. Journal of the American College of Cardiology, 73, 654-662.

https://doi.org/10.1016/j.jacc.2018.10.085

[51] Gattinoni, L., Pesenti, A., Mascheroni, D., Marcolin, R., Fumagalli, R., Rossi, F., et al. (1986) Low-Frequency Positive-Pressure Ventilation with Extracorporeal $\mathrm{CO}_{2}$ Removal in Severe Acute Respiratory Failure. JAMA, 256, 881-886. https://doi.org/10.1001/jama.256.7.881

[52] López-Saubidet, I., Rodríguez, P.O., Maskin, P., Attie, S., Bonelli, I. and Valentini, R. (2011) Utilization of Extracorporeal Membrane Oxygenation in Late Stage of the Acute Respiratory Distress Syndrome. Medicina Intensiva, 35, 448-450. https://doi.org/10.1016/j.medin.2010.12.007

[53] Repesse, X., Charron, C. and Vieillard-Baron, A. (2015) Acute Corpulmonale in ARDS: Rationale for Protecting the Right Ventricle. Chest, 147, 259-265. https://doi.org/10.1378/chest.14-0877

[54] Terragni, P.P., Del Sorbo, L., Mascia, L., et al. (2009) Tidal Volume Lower than 6 $\mathrm{ml} / \mathrm{kg}$ Enhances Lung Protection: Role of Extracorporeal Carbon Dioxide Removal. Anesthesiology, 111, 826-835. https://doi.org/10.1097/ALN.0b013e3181b764d2

[55] Angus, D.C., Linde-Zwirble, W.T., Lidicker, J., Clermont, G., Carcillo, J. and Pinsky, M.R. (2001) Epidemiology of Severe Sepsis in the United States: Analysis of Incidence, Outcome, and Associated Costs of Care. Critical Care Medicine, 29, 1303-1310. https://doi.org/10.1097/00003246-200107000-00002 